Original Research Article

\title{
A study of adverse drug reactions among pulmonary tuberculosis patients treated under dots in a tertiary care hospital
}

\author{
Priyadarshini Bai G. ${ }^{1 *}$, Ravikumar P. ${ }^{1}$, Umme Salma $^{2}$
}

\begin{abstract}
${ }^{1}$ Department of Pharmacology, Sri Siddhartha Medical College, Tumakuru, Karnataka, India ${ }^{2}$ Department of Pharmacology, CIMS, Chamarajanagara, India
\end{abstract}

Received: 08 February 2017 Accepted: 23 February 2017

*Correspondence to: Dr. Priyadarshini Bai G., Email: ravi_darshini@yahoo.co.in

Copyright: (C) the author(s), publisher and licensee Medip Academy. This is an openaccess article distributed under the terms of the Creative Commons Attribution NonCommercial License, which permits unrestricted noncommercial use, distribution, and reproduction in any medium, provided the original work is properly cited.

\begin{abstract}
Background: DOTS under RNTCP is the current treatment available for Pulmonary Tuberculosis. This treatment exhibit a greater level of efficacy with a small degree of toxicity. The present study aims to determine demography of patients with pulmonary tuberculosis and to study the ADRs caused by anti tubercular drugs and to assess the causality and severity of the reported ADRs.

Methods: We studied cases of Pulmonary Tuberculosis diagnosed and treated under category I DOTS at Department of Pulmonary Medicine for the period of one year (during 2015). Adverse effects observed during treatment course were recorded in standard 'Adverse Drug Event Reporting Form'. ADRs were also assessed for their causality and severity by using WHO-UMC criteria and Hartwig's scale.

Results: Pulmonary cases accounted for $67.6 \%$ of total TB cases. Among 434 cases of pulmonary tuberculosis $33(7.6 \%)$ patients were defaulters; among them $3(9.5 \%)$ cases were defaulters due to ADRs. In our study 96 patients developed 123 ADRs of various types and most of the ADRs noted within first 2 weeks of initiation of treatment. Gastritis was the most common ADRs $(28 / 22.7 \%)$ followed by anorexia $(26 / 21.1 \%)$.

Conclusions: In our study $22.1 \%$ of patients developed ADRs. ADRs recorded in our study were categorised under 'probable' and 'possible' causes and severity assessment showed $48 \%$ are moderate and $52 \%$ are 'mild' in nature. Still ADRs accounted for $9 \%$ default rate. Hence implementations of good patient care oriented programs are needed for early diagnosis and to reduce default rate and drug resistance.
\end{abstract}

Keywords: Hartwig's scale, Naranjo's causality assessment scale, Pulmonary Tuberculosis

\section{INTRODUCTION}

The WHO declared TB as a global health emergency in 1996. ${ }^{1}$ Tuberculosis is a major public health problem in India. Our country bear the burden of one-fifth of the global TB incident cases and topping the list. ${ }^{2}$ As per WHO estimate, 9 million people globally develop active TB and 1.7 million die of it annually. ${ }^{3}$ It is estimated that annually around 330,000 Indians die due to TB. ${ }^{4}$

Pulmonary tuberculosis is the most common presentation of tuberculosis disease, mode of spread being droplet inhalation. Mycobacterium may spread to any organ of the body through lymphatic or haematogenous dissemination and lie dormant for years at a particular site before causing disease. Manifestations may relate to the system involved, or simply as prolonged fever and nonspecific systemic symptoms.

Treatment of Tuberculosis was a challenge for clinicians in the past. After many studies it was concluded that multiple drugs and prolonged treatment is the key for successful treatment. DOTS was introduced in 1993 in India as part of RNTCP. ${ }^{5}$ One of the key component of DOTS therapy is the standard anti TB short course chemotherapy regimen, which requires continually taking drug combinations of Isoniazid (INH), Rifampicin(RFP), Pyrazinamide (PZA), Ethambutol (EMB), and/or Streptomycin (SM) every other day for 6-9 months. ${ }^{6}$

Though ATT has good therapeutic effects, studies have showed these multidrug regimens can cause undesirable 
adverse drug reactions (ADRs) of varying degrees of severity, such as allergic reactions, gastrointestinal (GI) disorders, hepatotoxicity, neurological disorders, arthralgia and so on. ${ }^{7-10} \mathrm{~A}$ study done by Chukanov et al suggests that more than $5 \%$ of the patients on anti-tubercular drugs (ATT) develop ADRs. ${ }^{11}$ None of the anti-TB drugs is safe but rarely these ADRs are life threatening. A study done by Awofeso N showed ADRs can be a potential factor leading to treatment non adherence. ${ }^{12}$ ADRs increase patient suffering and incur substantial additional costs because of added outpatient visits, tests, and in more serious instances hospitalizations. ${ }^{9}$ So close monitoring of adverse drug reactions and its effective management is needed. Pharmacovigilance activities can help in obtaining real information of safety and effectiveness of medicines when they are being used in the population. ${ }^{13}$

Most of the time treatment of ATT induced ADRs are conservative. For Minor side effects treatment should be continued with symptomatic measures such as antacids, antihistamines, antiemetics, or analgesic. If major side effects occur, the regimen or the offending drug if identified must be stopped. Further management depends on the nature of side effects and may have to be done in a hospital. $^{14}$

The present study aims to determine the presentation and outcome of patients with pulmonary tuberculosis treated with category I DOTS and to identify the incidence and pattern of ADRs caused by anti tubercular drugs and to assess the causality and severity of the reported ADRs.

\section{METHODS}

Data was collected from cases of Pulmonary TB diagnosed at Sri Siddhartha Medical College Hospital and Research centre, Tumakuru during the year 2015 that are treated under DOTS. Demography of these patients was recorded. Treatment outcome was evaluated as cured, completed treatment, defaulted, failed, or died based on the definitions given by the WHO.

Inclusion Criteria for this study includes all cases of Pulmonary TB of all age groups and both sexes treated at our centre. Exclusion Criteria includes any cases of Drug resistant TB, Diabetes Mellitus, Ischemic Heart Disease, Chronic Kidney Disease and HIV co-infection, and Patients on cat II ATT and patients with previous history of allergy to anti-tubercular drugs.

All the patients of pulmonary tuberculosis were enrolled after taking their informed consent and monitored for ADRs. Patient profile was maintained to identify the patient demography, date of start and completion of treatment, record of follow-up, and incidence of ADRs, onset, management and outcome of the ADRs. Any adverse effects observed were recorded in the 'Adverse Drug Event Reporting Form' prepared by the CDSCO, Govt. of India. ADRs were also assessed for their causality and severity as per the standard algorithms. 434 cases were studied for ADR monitoring during the study period and causality was assessed using world Health Organization -Uppsala monitoring centre (WHO-UMC) and Naranjo's causality assessment scale. Severity was assessed by Hartwig's questionnaire.

The study was conducted after obtaining ethical clearance from institutional ethical committee. The statistical analysis was done by using descriptive analysis.

\section{RESULTS}

We subjected 2145 suspected cases for investigation to rule out tuberculosis during the year 2015. Among them 752 cases of TB were diagnosed. They were further classified as Sputum Positive Pulmonary TB $(n=456)$, Sputum Negative pulmonary TB $(n=53)$ and Extrapulmonary TB $(n=243)$. Pulmonary TB cases accounted for $67.6 \%$ of total cases (Table 1 ).

Table 1: Total number of pulmonary and extrapulmonary cases.

\begin{tabular}{|c|c|c|c|}
\hline \multirow{2}{*}{$\begin{array}{l}\text { Total } \\
\text { number } \\
\text { of } \\
\text { TB } \\
\text { suspected } \\
\text { cases }\end{array}$} & \multicolumn{2}{|c|}{$\begin{array}{l}\text { Total number of cases } \\
\text { of pulmonary TB }\end{array}$} & \multirow{2}{*}{$\begin{array}{l}\text { Total } \\
\text { number of } \\
\text { Extra- } \\
\text { pulmonary } \\
\text { cases } \\
\text { diagnosed }\end{array}$} \\
\hline & $\begin{array}{l}\text { Number } \\
\text { of } \\
\text { sputum } \\
\text { positive } \\
\text { cases }\end{array}$ & $\begin{array}{l}\text { Number of } \\
\text { x-ray positive, } \\
\text { smear } \\
\text { negative } \\
\text { cases }\end{array}$ & \\
\hline 2145 & $\begin{array}{l}456 \\
(60.6 \%)\end{array}$ & $53(7.04 \%)$ & $243(32.2 \%)$ \\
\hline
\end{tabular}

After inclusion and exclusion criteria 434 cases of Pulmonary TB cases were included in the study. Among them $285(65.6 \%)$ were male and $149(34.4 \%)$ were female patients and most of the patients were in the age group of 20-40 years (Table 2).

Table 2: Age and sex distribution of pulmonary TB cases.

\begin{tabular}{|llll|}
\hline Age & Sex & Total \\
\hline$<20$ years & Male & Female & \\
\hline 21-40 years & 155 & 46 & 109 \\
\hline 41-60 years & 52 & 67 & 222 \\
\hline$>60$ years & 15 & 29 & 81 \\
\hline Total & $285(65.6 \%)$ & 07 & 22 \\
\hline
\end{tabular}

Among 434 cases of Pulmonary tuberculosis who were on DOTS treatment, $382(88 \%)$ patients completed treatment, $33(7.6 \%)$ patients defaulted, 14 (3.2\%) patients died and there were $05(1.2 \%)$ cases of treatment failure (Table 3). Out of 33 defaulters, the most common reason for defaulting treatment was irregular treatment 12 (36.3\%), alcohol abuse $14(42.4 \%)$ and $3(9.5 \%)$ was due to ADRs (Table 4). 
Table 3: Treatment outcome of total subjects.

\begin{tabular}{|lll|}
\hline Treatment outcome & $\begin{array}{l}\text { Results } \\
\text { (number of } \\
\text { patients })\end{array}$ & $\begin{array}{l}\text { Percentage } \\
(\%)\end{array}$ \\
\hline Treatment completed & 382 & $(88 \%)$ \\
\hline Defaulted & 33 & $(7.6 \%)$ \\
\hline Died & 14 & $(3.2 \%)$ \\
\hline Failure & 5 & $(1.2 \%)$ \\
\hline Total & $\mathbf{4 3 4}$ & $\mathbf{( 1 0 0 \% )}$ \\
\hline
\end{tabular}

Table 4: Reasons for Default.

\begin{tabular}{|ll|}
\hline Reason for default & Number of patients (\%) \\
\hline Irregular treatment & $12(29.5 \%)$ \\
\hline Alcohol & $14(23.5 \%)$ \\
\hline Refused DOTS drugs & $4(11.7 \%)$ \\
\hline Stopped due to ADRs & $3(9.5 \%)$ \\
\hline Total & $\mathbf{3 3 ( 1 0 0 \% )}$ \\
\hline
\end{tabular}

Our study revealed that out of 434 patients, 96 patients developed 123 ADRs of various types. Among them, most of ADRs were observed in males $(68 / 70.8 \%)$ and remaining $(28 / 29.2 \%)$ among females. The overall incidence of ADRs was $22.11 \%$.

We categorized ADRs according to the systems affected like gastrointestinal system, skin, nervous system and other systems like vestibular system, musculo-skeletal system etc. Majority of ADRs were related to gastrointestinal system (67 cases) followed by central nervous system (20 cases), skin (9 cases) and other systems (27 cases). Gastritis was the most common ADR $(28 / 22.7 \%)$ followed by anorexia $(26 / 21.1 \%)$, weakness (18/14.63\%), Hepatitis (13/10.56\%), peripheral neuropathy (11/8.9\%) and skin reactions (9/7.3\%) (Figure 1). Among $95 \%$ of the cases, the suspected drug was continued in spite of the ADR, without any complications.

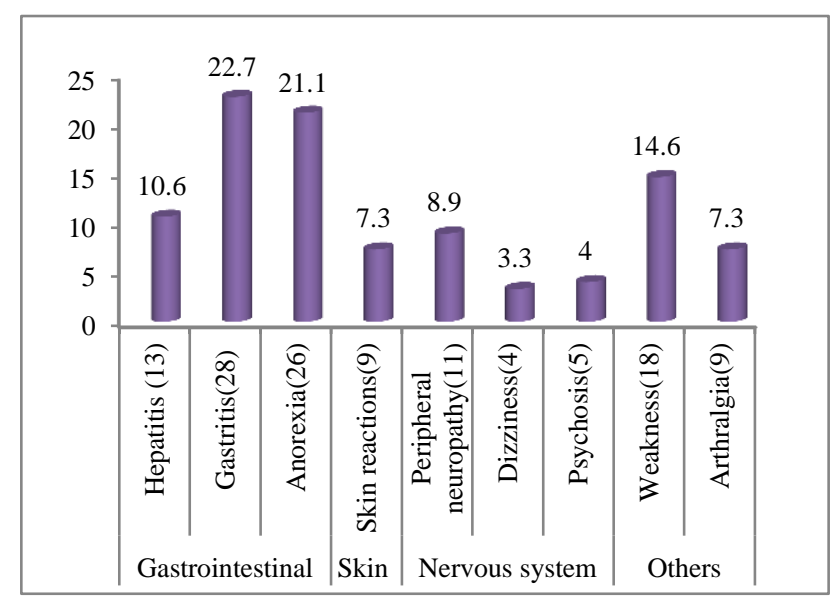

Figure 1: The figure depicts the frequency of distribution of adverse drug reaction to AntiTubercular drugs.
We studied onset of ADRs during the course of treatment. $13(10.5 \%)$ cases of the ADRs occurred on the first day of the treatment and $43(34.9 \%)$ ADRs occurred within a week of treatment, $56(45.5 \%)$ in the second week, $11(8.9 \%)$ in the third week of the initiation of anti tubercular therapy.

Causality assesment of ADRs, revealed majority of them were found to be probable $(52 \%)$ followed by possible (42\%) (assessed as per WHO-UMC and Naranjo's scales). The Naranjo algorithm is used widely in the causality assessment of ADRs. It is based on the score calculated on the basis of points assigned to each of the ten questions that comprises the table. These ADRs were classified into different levels like mild, moderate or severe based on the Modified Hartwig and Siegel scale. The severity assessment of ADRs showed that $48 \%$ reactions were moderate and $52 \%$ were of the 'mild' in nature as per the Hartwig et al scale.

\section{DISCUSSION}

We studied 2145 suspected cases of tuberculosis at our site during the year 2015. Among 752 cases of TB diagnosed, 456 had Sputum Positive Pulmonary TB, 53 had Sputum Negative pulmonary TB and 243 had Extrapulmonary TB. Sputum positive Pulmonary TB accounted for $60.6 \%$, Sputum negative Pulmonary TB $7 \%$ and extra-pulmonary cases accounted for $32.2 \%$ of total TB cases. Our study is in consistent with study done by chandir.s. ${ }^{17}$ In the present study tuberculosis was seen more in males compared to females. Similar results were seen in other studies. ${ }^{18,19}$ However, Mir Azam Khan reported equal number of cases in both sex. ${ }^{20}$

Among 434 cases of Pulmonary tuberculosis studied, 382 $(88 \%)$ patients completed treatment, $33(7.6 \%)$ patients defaulted, $14(3.2 \%)$ patients died and there was 05 $(1.2 \%)$ case of treatment failure. Similar study conducted by Chandir S showed higher Default rate $(34.5 \%)$ and only $59.8 \%$ patients had completed treatment and more treatment failures $(5.2 \%)$ compared to our study and finally $3.2 \%$ patients died during treatment in this study. ${ }^{17}$

The most common reason for default in our study was irregular treatment $(36.3 \%)$ followed by alcohol abuse (42.4\%) and ADRs (9\%). Chandrashekaran reported illiteracy, alcohol intake and smoking as the causes for default. $^{21}$ The study by Tekle reported that default was $11.3 \%$, the reason being lack of family support, inadequate knowledge of treatment duration and side effects of medication. ${ }^{22}$

Out of 434 patients enrolled in the study, 96 patients developed 123 ADRs $(22.1 \%)$. The highest number of ADRs $(68 / 70.8 \%)$ was observed in males which are in contrast to the study by Yee and Shakya et al which showed female gender as a risk factor for the occurrence of ADRs due to anti-TB drugs. ${ }^{23}$ But in the study, by 
D.K.Tak et al, males developed more ADRs, which could be due to majority of males included in the study. ${ }^{24}$

In our study, 331 patients were under 40 years of age (76.2\%) followed by 81 patients at age of 40-60 (18.66\%) and 22 were in more than 60 years age group $(5 \%)$. This result is in contrast to the study by Yee et al where age over 60 years was associated with increased incidence of ADRs due to anti TB drugs. A study conducted by Daphne et al showed that ADRs due to anti tubercular drugs occurred in patients above the age of 60 years. But in our Study, majority of ADRs were observed in patients below 60 years of age. This may be due to less number of patients in above 60 yrs age group in our study. We noted $115(93.5 \%)$ cases of ADRs in patients less than 40 years and 40-60 years of age group.

In our study we timed ADRs during treatment course. We noted $13(10.5 \%)$ of the ADRs occurred on the first day of the treatment 43 ADRs $(34.9 \%)$ occurred within a week of treatment, $56(45.5 \%)$ in the second week, 11 $(8.9 \%)$ in the third week of the initiation of anti tubercular therapy. Most of the ADRs were noted before 2 weeks of initiation of treatment. So intensive monitoring for ADRs required during first two weeks of treatment. We suggest educating patients regarding side effects of these drugs and when to report to doctor and arrange for a follow up visit between 1-2 weeks after initiation of treatment.

The highest reported ADR was gastritis 28 (22.7 \%) which is in accordance to the study by Dhingra et al, where it was around 53\%. ${ }^{9}$ Anorexia was the second common ADR noted 26(21.1\%). A study conducted by Sainul Abideen $\mathrm{P}$ et al reveals that, GI system, liver and biliary system is the most frequent organ system affected by ADRs. ${ }^{13}$ Multiple drug therapy was noticed to be a major predisposing factor for developing GI side effects.

Other ADRs noted were generalised weakness, Hepatitis and Peripheral neuropathy in our study population, whose occurrence was comparable to that found in the study conducted by Dhingra et al. ${ }^{9}$

On evaluation of the causality of ADRs, a majority of the reactions were probable (52\%), followed by possible (42\%). There were no definite reactions. Gholami et al also supported the same findings that the probable reaction was the more. ${ }^{15}$

The reported ADRs were classified into different levels like mild, moderate or severe based on the Modified Hartwig and Siegel scale. The severity assessment of ADRs showed that $48 \%$ reactions were moderate and $52 \%$ were of the 'mild' nature as per the Hartwig et al scale. A study by Gholami et al shows similar result in which most of the adverse drug reaction are of moderate severity. ${ }^{15}$ A study by Tak D K also supported this result. $^{16}$

\section{CONCLUSION}

This study was conducted to analyse Pulmonary TB cases and to look for ADRs of ATT in our hospital. Pulmonary Tuberculosis accounted for predominant type of TB $(67.6 \%)$ With good percentage of patients completed treatment $(88 \%)$. Our study revealed 33 (7.6\%) default rate. Treatment irregularities and alcohol abuse and ADRs are the three most common reasons for default. The side effects may steer the patient to make a judgment for stopping the medications and finally the occurrence of drug resistance and leading to amplified health care cost. We noticed more number of ADRs in males possibly due to more male patients in the study. Gastro-intestinal system was the most common system involved in ADRs. Most of the ADRs reported in our study were categorized as mild to moderate severity. In majority of the cases, ATT was continued in spite of the ADRs, without any complications. Most of the ADRs were noted within 2 weeks of initiation of treatment. So intensive monitoring for ADRs required during first two weeks of treatment. Hence implementation of good patient care oriented program is need of the hour and arrange for a follow up visit before 2 weeks of initiation of treatment.

\section{ACKNOWLEDGEMENTS}

Authors would sincerely thank his patients for their cooperation and support. $\mathrm{He}$ is also grateful to the institution, Sri Siddhartha Medical College for immense support.

\section{Funding: No funding sources}

Conflict of interest: None declared

Ethical approval: The study was approved by the Institutional Ethics Committee

\section{REFERENCES}

1. WHO report 2009 Global tuberculosis control Epidemiology, strategy, financing. Geneva: World Health Organization; 2009.

2. Bhargava A, Pinto L, Pai M. Mismanagement of tuberculosis in India: Causes, con-sequences, and the way forward. Hypothesis. 2011:9:e7.

3. Parthasarathi G, Hansen KN, Nahata MC. Textbook of clinical pharmacy practice. India: Universities press private Ltd; 2004:104-22.

4. Schaberg T, Rebhan K, Lode H. Risk factors for side effects of isoniazid, and pyra-zinamide in patients hospitalized for pulmonary tuberculosis. Eur Respir J. 1996;9:2026-30.

5. Balasubramanian VN, Oommen K, Samuel R. DOT or not? Direct observation of anti-tuberculosis treatment and patient outcomes, Kerala State, India. Int J Tuberc Lung Dis. 2000;4:409-13.

6. World Health Organization. An expanded DOTS framework for effective tuberculosis control. Stop TB Communicable Diseases. Geneva: WHO Press; 2002:120. 
7. Zaka Ur Rehman Z, Jamshaid M, Chaudhry A. Clinical evaluation and monitoring of adverse effects for fixed multidose combination against single drug therapy in pulmonary tuberculosis patients. Pak J Pharm Sci. 2008;21:185-94.

8. Vieira DE, Gomes M. Adverse effects of tuberculosis treatment: Experience at an outpatient clinic of a teaching hospital in the city of São Paulo, Brazil. JBras Pneumol. 2008;34:1049-55.

9. Dhingra VK, Rajpal S, Aggarwal N, Aggarwal JK, Shadab K, Jain SK. Adverse drug reactions observed during DOTS. J Commun Dis. 2004;36:251-9.

10. Marra F, Marra CA, Bruchet N, Richardson K, Moadebi S, Elwood RK, et al. Adverse drug reactions associated with first-line anti-tuberculosis drug regimens. Int J Tuberc Lung Dis. 2007;11:868-75.

11. Chukanov VI, Kaminskaia GO, Livchane E. Frequency and pattern of adverse reactions due to treatment of patients with pulmonary tuberculosis with antitubercular reserve drugs. Probl Tuberk Bolezn Legk. 2004;10:610.

12. Awofeso N. Anti-tuberculosis medication side-effects constitute major factor for poor adherence to tuberculosis treatment. Bull World Health Organ. 2008;86:BD.

13. Abideen SP, Chandrasekaran K, Maheswaran U, Vijayakumar A, Kalaiselvan V, Mishra A, et al. Implementation of Self Reporting Pharmacovigilance in Anti Tuber cular Therapy Using Knowledge Based Approach. J Pharmacovigilance. 2013;1:101.

14. Xia YY, Hu DY, Liu FY, Wang XM, Yuan YL, Tu DH. Design of the anti-tuberculosis drugs induced adverse reactions in China national Tuberculosis prevention and cotroscheme study. BMC Public Health. 2010;10:267-76.

15. Gholami K, Kamali E, Hajiabdolbagh Mi, Shalviri G. Evaluation of antituberculosis induced adverse reactions in hospitalized patients. Pharmacy Practice. 2006;4:134-8.

16. Tak DK, Acharya LD, Gowrinath K, Rao PGM, Subish P. Safety Evaluation Of Antitubercular Therapy Under Revised National Tuberculosis
Control Programme In India. Journal of Clinical and Diagnostic Research. 2009;3:1395-401.

17. Chandir S, Hussain H, Amir M, Lotia I, Khan AJ, Salahuddin N, et al. Extra pulmonary Tuberculosis: A retrospective review of 194 cases at a tertiary care hospital in Karachi, Pakistan. JPMA; 2010:1-6.

18. Okanurak K, Kitayapor D, Wanarangsikul W, Koompong C. Effectiveness of DOT for tuberculosis treatment outcome: a prospective study in Bangkok, Thailand Int $\mathrm{J}$ Tuberc Lung QQ disease. 2007;11(7):762-8.

19. Diel R, Niemann S. Outcome of tuberculosis treatment in Hamburg: a survey 1997-2001. Int J Tuberc Lung Dis. 2003;7(2):124-31.

20. Khan MA, Basit A, Javaid ZA. Outcome of tuberculosis patients registered during 2007 in major teaching hospitals of Peshawar. JPMI. 2009;23(04):358-62.

21. Chandrashekaran V, Gopi PG, Subramani R, Thomas A, Jaggarajamma K, Narayanan PR. Default during the intensive phase of treatment under DOTS programme. Indian J Tuberc. 2005;52:197-02.

22. Tekle B, Mariam DH, Ali A. Defaulting from DOTS and its determinants in three districts of Arsi Zone in Ethiopia lnt J Tuberc Lung Dis. 2002;6(7):573-9.

23. Yee D, Valiquette C, Pelletier M, Parisien I, Rocher I, Menzies D. Incidence of serious side effects from first- Line antitiberculosis drugs among patients treated for active tuberculosis, Am J Respir Crit Care Med. 2003;167:1472-7.

24. Tak DK. Safety Evaluation of Antitubercular Therapy Under Revised National Tuberculosis Control Programme In India, JCDR. 2009;3:1395401.

25. Daphne Y, Marthe P. Incidence of serious side effects from First-line antituberculosis drugs among patients treated for Active Tuberculosis, Am J Resp Crit Care Med. 2003;167:1472-7.

Cite this article as: Priyadarshini BG, Ravikumar P, Salma U. A study of adverse drug reactions among pulmonary tuberculosis patients treated under dots in a tertiary care hospital. Int J Basic Clin Pharmacol 2017;6:779-83. 